\title{
The first aeromagnetic survey in the Arctic: results of the Graf Zeppelin airship flight of 1931
}

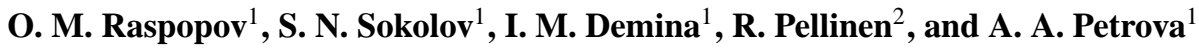 \\ ${ }^{1}$ St. Petersburg Filial of N.V. Pushkov Institute of Terrestrial Magnetism, Ionosphere and Radiowave \\ Propagation of RAS, St. Petersburg, Russia \\ ${ }^{2}$ Finnish Meteorological Institute, P.O. Box 503, 00101 Helsinki, Finland
}

Correspondence to: O. M. Raspopov (oleg@or6074.spb.edu) and R. Pellinen (risto.pellinen@ presentor.fi)

Received: 14 August 2012 - Revised: 14 February 2013 - Accepted: 17 February 2013 - Published: 13 March 2013

\begin{abstract}
In July of 1931, on the eve of International Polar Year II, an Arctic flight of the Graf Zeppelin rigid airship was organized. This flight was a realization of the idea of F. Nansen, who advocated the use of airships for the scientific exploration of the Arctic territories, which were poorly studied and hardly accessible at that time. The route of the airship flight was Berlin - Leningrad - Arkhangelsk - Franz Josef Land Severnaya Zemlya - the Taimyr Peninsula - Novaya Zemlya - Arkhangelsk - Berlin. One of scientific goals of the expedition was to measure the $H$ and $D$ geomagnetic field components. Actually, the first aeromagnetic survey was carried out in the Arctic during the flight. After the expedition, only preliminary results of the geomagnetic measurements, in which an anomalous behavior of magnetic declination in the high-latitude part of the route was noted, were published. Our paper is concerned with the first aeromagnetic measurements in the Arctic and their analysis based on archival and modern data on the magnetic field in the Barents and Kara sea regions. It is shown that the magnetic field along the flight route had a complicated structure, which was not reflected in the magnetic charts of those times. The flight was very important for future development of aero- and ground-based magnetic surveys in the Arctic, showing new methods in such surveys.
\end{abstract}

1

\section{Introduction}

Attention to the necessity and importance of collective research efforts in the investigation of geophysical processes, including geomagnetic measurements, in the Arctic region had already been drawn when Polar Year I (1882-1883) was organized. Later, a number of national and international expeditions were carried out with the aim of exploring the Arctic territories and studying the geophysical processes on these territories. A fast development of aviation (and then airship building) in the first decades of the 20th century opened up new possibilities for penetration to hardly accessible Arctic latitudes, including the North Pole. For instance, on 12 May 1926, the Norge airship commanded by Umberto Nobile (on an expedition organized by Roald Amunsen and Lincoln Ellsworth) reached the North Pole (Wichman, 2002).

In the 1920s, the International Association for Exploring the Arctic by Means of Airships, or "Aeroarctic" was created.
It was initiated by a German aeronautical engineer Hugo Eckener, who advocated the use of airships for the exploration of the Arctic. This idea was supported by a well-known polar explorer Fridtjof Nansen, who issued a memorandum in 1930 in which the importance of exploration of the Arctic areas and investigation of the processes occurring in them was emphasized (Nansen, 1930).

F. Nansen was elected president of Aeroarctic, and his scientific reputation was extremely helpful in the realization of the idea to use airships for exploring the Arctic. To carry out an Arctic flight with scientific aims, the Graf Zeppelin airship constructed in Germany was used. In 1928-1929 this airship made a number of transatlantic flights. With a maximum bunkerage capacity of about 1060000 cubic feet of Blau gas (illuminating gas) for fuel, the Graf Zeppelin's calculated radius of action was 9600 miles $(15400 \mathrm{~km})$.

The original plan of the Graf Zeppelin flight at the Arctic latitudes envisioned a rendezvous with the submarine 


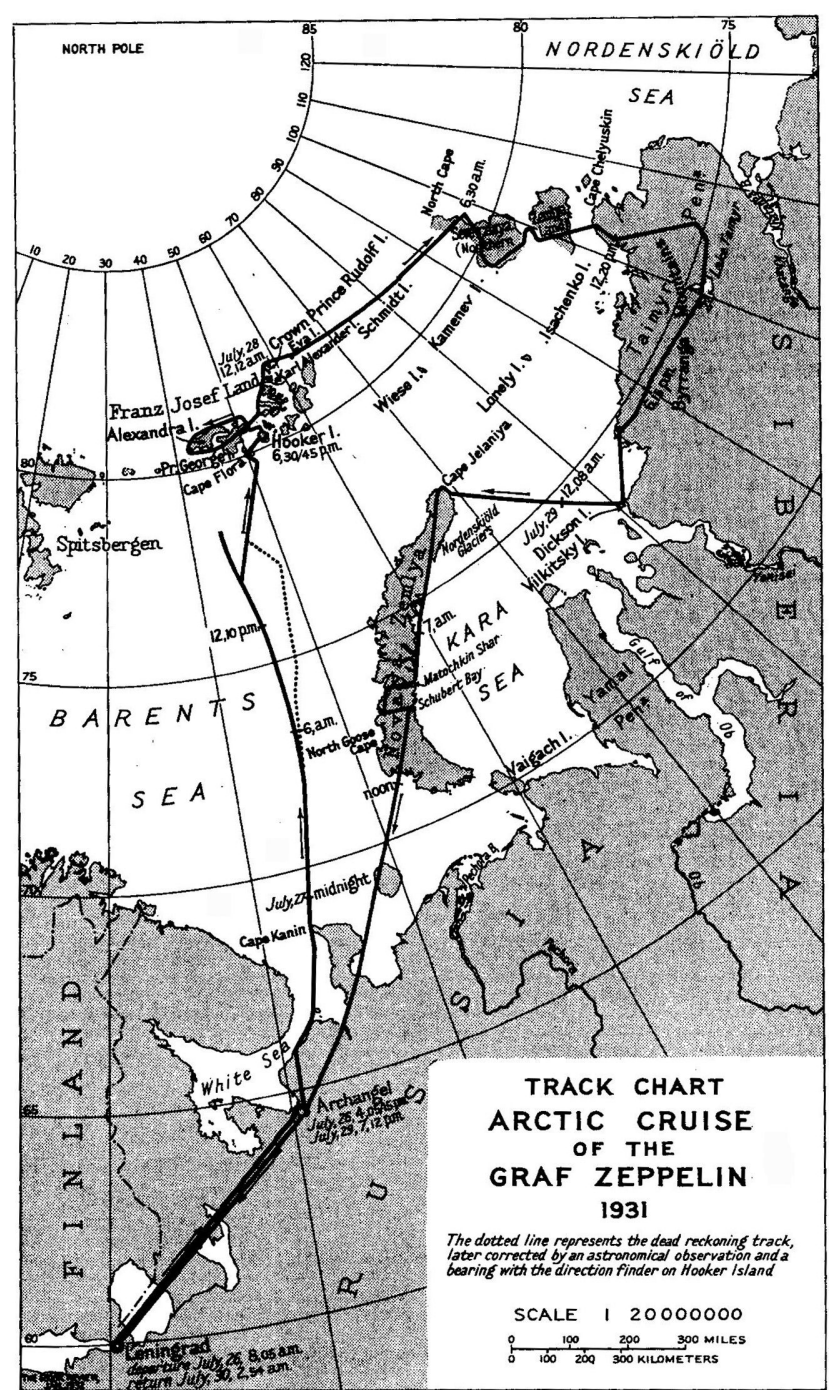

Figure 1. Route of the Graf Zeppelin Arctic flight.

Nautilus, which had to arrive at a specified location of the Arctic under ice (Wilkins, 1931; Wichman, 2002). An exchange of mail between Nautilus and the airship was suggested. The polar expedition was largely financed with revenue from stamp collectors. However, this project failed because of technical difficulties with the submarine. Eventually, the route of the Graf Zeppelin flight was planned to be as follows: Berlin - Leningrad - Franz Josef Land - Severnaya Zemlya - over the Taimyr Peninsula to the observatory of Dikson Island, to the strait Matochkin Shar on Novaya Zemlya. Then the airship had to return to Germany via Leningrad. The flight took place in July of 1931 on the eve of Polar Year II (1932-1933). As earlier planned, the mail exchange had to occur but now the rendezvous was to take place with a surface vessel at the northern point of the flight. The mail to Franz Josef Land had to be delivered by the Russian icebreaker Malygin which was on a tourist cruise to the Arctic.

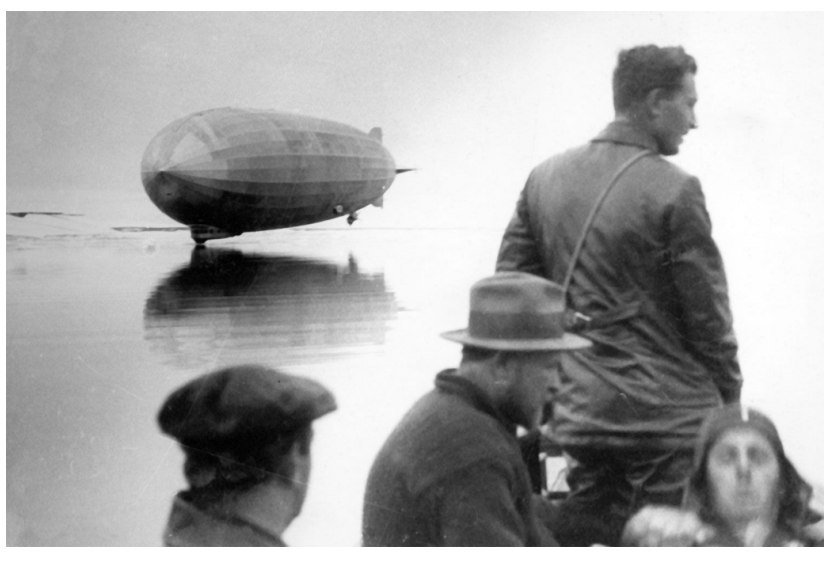

Figure 2. Graf Zeppelin descending to the water surface near Franz Josef Land. Umberto Nobile is standing in the boat.

The head of Aeroarctic, F. Nansen, suddenly died before the flight began, and Aeroarctic was headed by H. Eckener. The airship Graf Zeppelin, owing to Eckener's enthusiasm, was constructed and its Arctic flight took place (Eckener, 1980).

The Arctic flight of the airship became an international project in which a team including German, Soviet, American, and Swedish participants took part. The airship flight started on 26 July 1931, and ended on 30 July 1931. The flight route is shown in Fig. 1. As planned, the airship met the icebreaker Malygin near Franz Josef Land and exchanged mail. A photo that shows the moment of the airship descending to the water surface was saved and is shown in Fig. 2. At the foreground of Fig. 2 there are participants of the meeting who arrived at the icebreaker. Umberto Nobile is standing in the boat.

The scientific goals of the Arctic expedition of Graf Zeppelin were as follows:

- Mapping and geographic exploration of poorly charted Arctic areas;

- Meteorological observations in the Arctic, including launching of several radiosondes;

- Measurement of the earth's magnetic field in the Arctic region

The scientific team of the expedition included:

- Hugo Eckener - a German manager of the Luftschiffbau Zeppelin and leader of the expedition;

- Prof. Rudolf Lazarevich Samoilovich - a Soviet polar explorer and scientific leader of the expedition;

- Prof. Ludwig F. Weickmann - Director of the Geophysical Institute, University of Leipzig, and a chief meteorologist of the expedition;

- Prof. Pavel Alexandrovich Molchanov - a Soviet meterologist and inventor of the radiosonde ("Molchanov 
balloon"). The radiosondes were launched during the flight;

- Dr. Aschenbrenner - a German engineer, aerogeodicist, and photographer from Munich;

- Dr. W. Basse - a German engineer, aerogeodicist, and photographer for Carl Zeiss Co.;

- Dr. Ludwig Kohl-Larsen - a German physician and explorer, zoologist, and anthropologist;

- Lincoln Ellsworth - a polar explorer and representative of the American Geographical Society;

- Lieutenant Commander Edward H. Smith - representative of the United States Coast Guard and the International Ice Patrol;

- Dr. Gustaf S. Ljungdahl - a representative of the Swedish Hydrographic Office, in charge of magnetic observations;

- Captain Walther Bruns - General Secretary of Aeroarctic;

- Ernst Teodorovich Krenkel - a Soviet polar explorer and noted radio operator;

- Fyodor F. Assberg - a Soviet aviation engineer, later head of the USSR Bureau of Airship Construction.

This paper is concerned with geomagnetic observations on board the airship and their analysis based on the available ground-based data for the epoch 1931 as well as modern ideas on the geomagnetic field structure in the region of the flight. It is important to emphasize that during the expedition, the first aeromagnetic surveys in the Arctic were carried out. According to the plan of the expedition, the airship had to descend to the water surface near Domashniy Island, not far from the western coast of Severnaya Zemlya. On the Island, the base of the Polar expedition headed by G. A. Ushakov was situated. There a participant of the expedition, a wellknown geologist and discoverer of Norilsk copper-nickel deposits, N. N. Urvantsev, was meant to be taken on board the airship. However, as reported by E. T. Krenkel, because of a blackout of the shortwave radiocommunication with the base during the flight from Franz Josef Land to Severnaya Zemlya, the expedition could not do this. The airship flew to the Taimyr Peninsula without landing. The radiocommunication blackout could be caused by geomagnetic and ionospheric disturbances on the flight route. Geomagnetic field disturbances could also affect the measurements of geomagnetic field components. In this paper we analyze the geomagnetic field disturbances during the time interval of the Arctic expedition of Graf Zeppelin on the basis of existing magnetic records for the time interval of the flight. This analysis has not been performed so far.
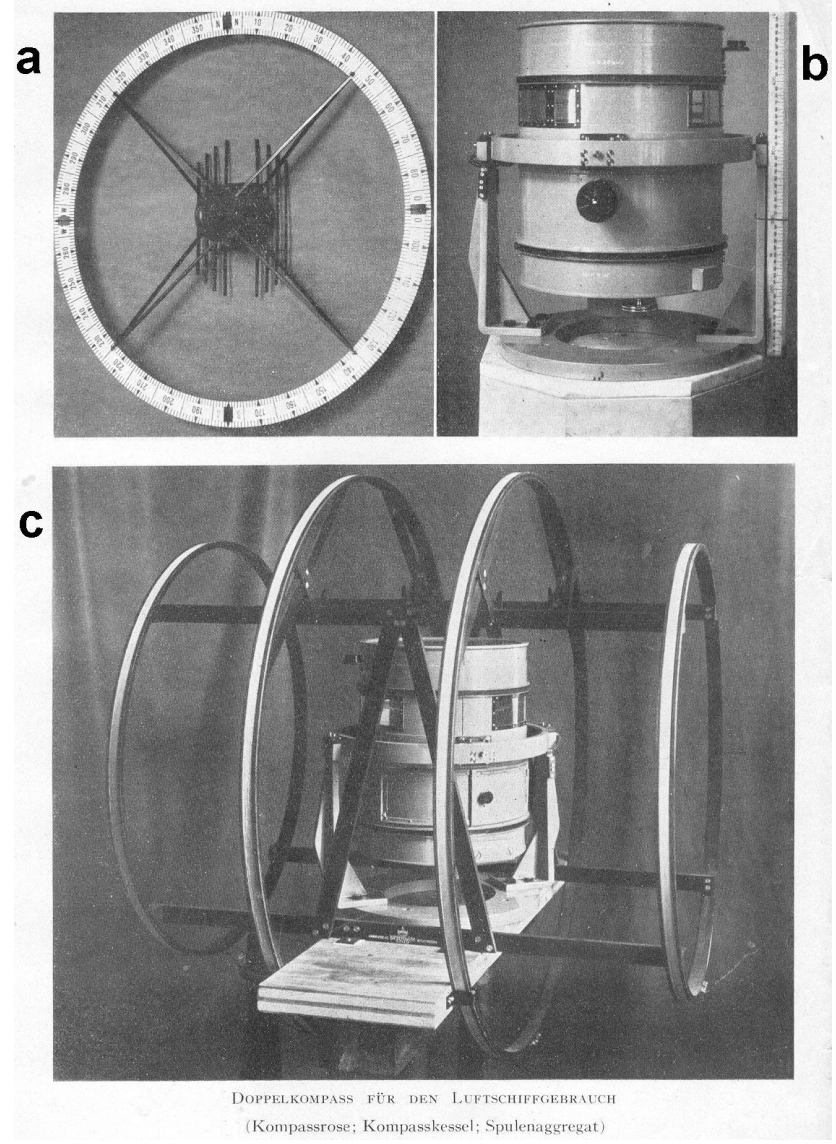

Figure 3. Double compass used to measure the geomagnetic field $H$ component on board the Graf Zeppelin airship: (a) - card, (b) - the external view of the instrument, (c) - calibration rings (Grotewahl, 1930).

\section{Procedure of geomagnetic measurements on board the Graf Zeppelin airship}

During the Arctic flight of Graf Zeppelin, measurements of geomagnetic field components, i.e., horizontal component $H$ and declination $D$, were performed. The geomagnetic measurements were carried out under the direction of Swedish scientist L. Ljungdahl and assisted by American participants L. Ellsworth and E. Smith.

\subsection{Measurements of horizontal component}

The horizontal geomagnetic field $H$ component was measured with a "double compass" loaned by the Carnegie Institute of Terrestrial Magnetism of Washington, DC. This instrument is shown in Fig. 3 (Grotewahl, 1930; Ljungdahl, 1931).

Before the flight to the Arctic, methodological investigations of the accuracy of $H$ component measurements and of the influence of the airship's field on the device readings were 


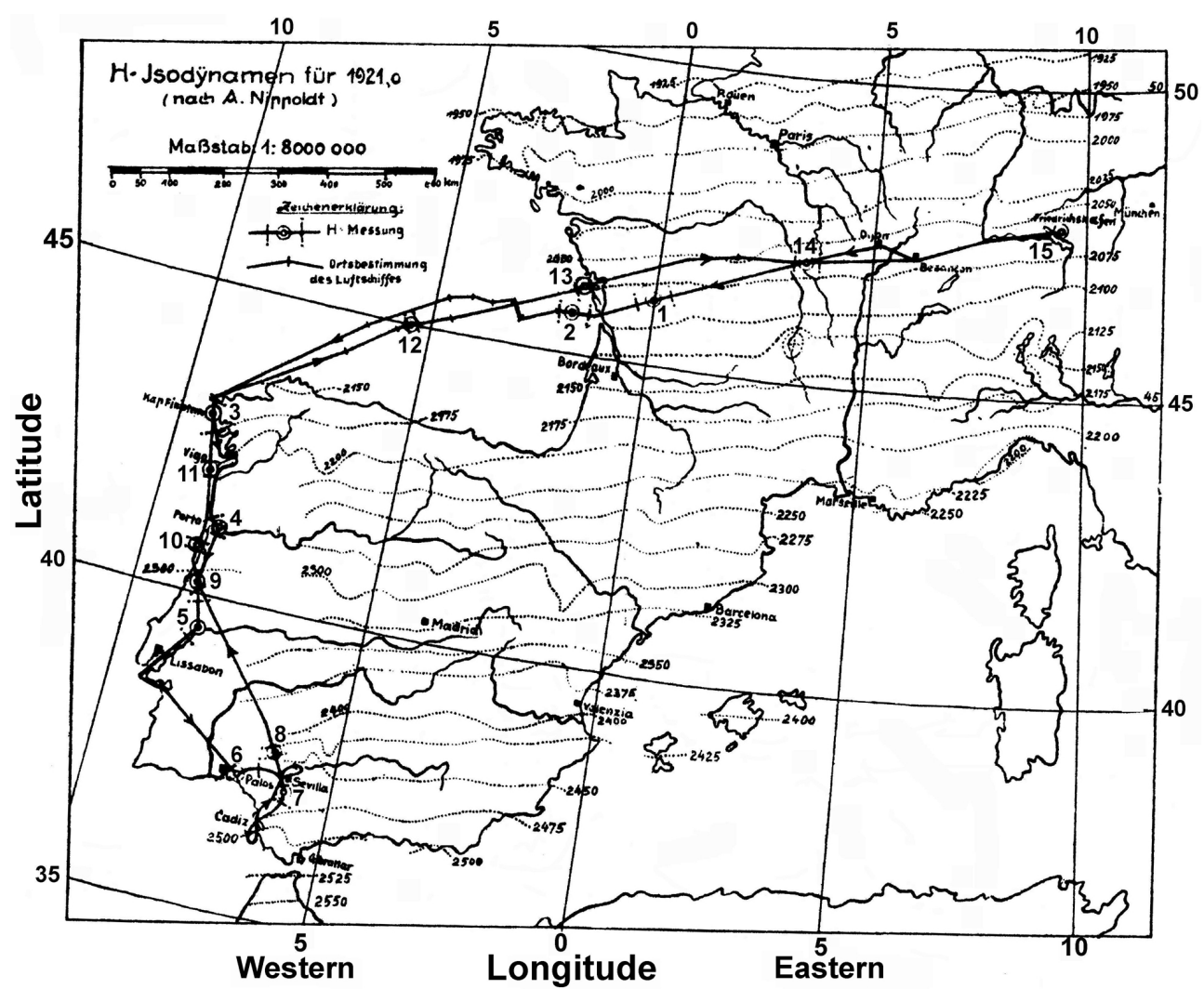

Figure 4. Map of the test flight of Graf Zeppelin over Europe (Grotewahl, 1930).

carried out. To this end, a test flight of Graf Zeppelin over the European territory from Germany to the south of Spain was held from 15 to 17 April 1930 (Fig. 4) (Grotewahl, 1930). Charts of the geomagnetic field $H$ component were available for this territory. During the flight, the double compass was placed in a cabin $8 / 10$ at the end of airship in the daytime, and in the saloon during night hours. All iron-containing objects were removed from the cabin. During the flight, the airship changed flight direction in order to estimate the compass deviation. Before and after the flight the device was calibrated in Potsdam.

The measurement inaccuracy at the majority of points, shown in Fig. 4, is not higher than 100-110 nT. Different device positions inside the gondola did not affect the accuracy of of the $H$ component determination. Only at point 1 was the difference $320 \mathrm{nT}$, and at points 3 and 4 it was 180 and $130 \mathrm{nT}$, respectively. In the opinion of M. Grotewahl (1930) who performed the measurements, such a discrepancy between the measured data and those given on the chart were due to local anomalies and secular geomagnetic field variations, which could be taken into account to an insufficient degree during chart plotting rather than inaccuracy of measurements.
Measurements of the $H$ component at a change of the flight direction during the European flight indicated that the airship field did not affect the compass deviation.

During the Arctic flight of Graf Zeppelin the double compass was placed in the same position as in the European flight (Ljungdahl, 1931). So it was expected that the inaccuracy of measurements of the $H$ component would not be greater than 100-150 nT. During the flight, the $H$ component measurements were taken every $4 \mathrm{~h}$.

\subsection{Measurements of declination $D$}

During the Arctic flight, magnetic declination $D$ was determined with a Thomson compass-rose with a fiber suspension according to Dr. Haussmann's model (Ljungdahl, 1931) by projection of the sun's shadow on the card. To exclude the influence of air currents, the rose was enclosed in a wooden box with an upper glass cover. A small hole in the cover through which the fiber was passed prevented horizontal fiber displacements.

To measure magnetic declination $D$, the instrument was placed in one of the two stern windows of the airship saloon in the position where the deviation was very small. During the flight, $D$ was measured only at 8 points because of difficulties in taking the sun's bearing from the instrument position. 
Table 1. Measurements of $H$ and $D$ during the airship Arctic flight and their comparison with $H$ and $D$ calculated from the IGRF-11 model.

\begin{tabular}{|c|c|c|c|c|c|c|c|c|c|c|c|}
\hline $\begin{array}{l}\text { Point } \\
\text { No. }\end{array}$ & Date, UT & $\begin{array}{c}\text { Time UT, } \\
\text { h, min }\end{array}$ & $\begin{array}{r}\text { Latitude } \\
{ }^{\circ} \mathrm{N}\end{array}$ & $\begin{array}{r}\text { Longitude } \\
{ }^{\circ} \mathrm{E}\end{array}$ & $\begin{array}{l}\text { Height of } \\
\text { flight, } m\end{array}$ & $\begin{array}{r}D, \\
\text { measured }\end{array}$ & $\begin{array}{r}D, \text { IGRF-11 } \\
\text { epoch } 1930\end{array}$ & $\Delta D$ & $\begin{array}{r}H, \\
\text { measured }\end{array}$ & $\begin{array}{r}H, \text { IGRF-11 } \\
\text { epoch } 1930\end{array}$ & $\Delta H$ \\
\hline 1 & 25.07 .1931 & $05: 40$ & 54 & 15.4 & 250 & -2.9 & -4.5 & 1.6 & - & 17776 & - \\
\hline 2 & 26.07 .1931 & 08:42 & 60.3 & 31.1 & 200 & & 4.2 & & 15380 & 15294 & 86 \\
\hline 3 & 26.07 .1931 & $11: 12$ & 61.8 & 34.7 & 250 & & 6.4 & & 14860 & 14672 & 188 \\
\hline 4 & 26.07 .1931 & $11: 28$ & 61.9 & 35.3 & 250 & & 6.8 & & 14860 & 14629 & 231 \\
\hline 5 & 26.07 .1931 & $14: 17$ & 63.8 & 37.1 & 250 & & 8.2 & & 13670 & 13828 & -158 \\
\hline 6 & 26.07 .1931 & $14: 31$ & 64.1 & 37.5 & 250 & & 8.6 & & 13790 & 13701 & 89 \\
\hline 7 & 26.07 .1931 & $16: 23$ & 64.6 & 40.6 & 200 & 12.3 & 10.4 & 1.9 & - & 13460 & - \\
\hline 8 & 26.07.1931 & $17: 16$ & 64.9 & 40.5 & 200 & & 10.4 & & 12720 & 13335 & -615 \\
\hline 9 & 26.07 .1931 & $18: 26$ & 66.2 & 41.4 & 200 & & 11.4 & & 12690 & 12780 & -90 \\
\hline 10 & 26.07.1931 & $20: 50$ & 67.5 & 42.9 & 150 & & 12.6 & & 12090 & 12209 & -119 \\
\hline 11 & 26.07 .1931 & $22: 04$ & 68.1 & 43.2 & 150 & & 13 & & 11810 & 11953 & -143 \\
\hline 12 & 27.07 .1931 & 00:07 & 69.4 & 43.8 & 200 & & 13.8 & & 11210 & 11401 & -191 \\
\hline 13 & 27.07 .1931 & $01: 26$ & 70.2 & 44.4 & 200 & & 14.5 & & 10910 & 11054 & -144 \\
\hline 14 & 27.07 .1931 & $02: 14$ & 70.7 & 44.6 & 200 & & 14.8 & & 10590 & 10842 & -252 \\
\hline 15 & 27.07 .1931 & 03:39 & 71.6 & 45.2 & 150 & & 15.4 & & 10190 & 10454 & -264 \\
\hline 16 & 27.07.1931 & $04: 36$ & 72.2 & 45.5 & 150 & & 15.8 & & 10040 & 10198 & -158 \\
\hline 17 & 27.07 .1931 & $05: 40$ & 72.9 & 45.8 & 150 & & 16.2 & & 9740 & 9902 & -162 \\
\hline 18 & 27.07 .1931 & $06: 55$ & 73.6 & 46 & 130 & & 16.5 & & 9620 & 9610 & 10 \\
\hline 19 & 27.07.1931 & $08: 15$ & 74.3 & 46 & 130 & & 16.7 & & 9350 & 9327 & 23 \\
\hline 20 & 27.07 .1931 & $09: 14$ & 74.7 & 46 & 150 & & 16.8 & & 9180 & 9165 & 15 \\
\hline 21 & 27.07.1931 & 10:08 & 75.5 & 45.9 & 150 & & 16.9 & & 8960 & 8846 & 114 \\
\hline 22 & 27.07.1931 & $11: 11$ & 76 & 45.6 & 150 & & 16.7 & & 8640 & 8661 & -21 \\
\hline 23 & 27.07 .1931 & $12: 12$ & 76.5 & 45 & 150 & & 16.4 & & 8400 & 8479 & -79 \\
\hline 24 & 27.07 .1931 & $13: 08$ & 77 & 44.5 & 150 & & 16.1 & & 7980 & 8297 & -317 \\
\hline 25 & 27.07.1931 & $14: 05$ & 77.4 & 45.4 & 150 & & 16.8 & & 7800 & 8104 & -304 \\
\hline 26 & 27.07 .1931 & $14: 42$ & 77.8 & 46.1 & 150 & 19.6 & 17.2 & 2.4 & - & 7918 & - \\
\hline 27 & 27.07.1931 & $15: 04$ & 78.1 & 46.9 & 200 & & 17.8 & & 7450 & 7767 & -317 \\
\hline 28 & 27.07 .1931 & $15: 19$ & 78.7 & 48 & 200 & 19.5 & 18.5 & 1 & - & 7486 & - \\
\hline 29 & 27.07 .1931 & $16: 00$ & 78.5 & 48 & 200 & & 18.5 & & 7220 & 7565 & -345 \\
\hline 30 & 27.07 .1931 & $17: 00$ & 79.8 & 50.8 & 200 & & 20.4 & & 6800 & 6941 & -141 \\
\hline 31 & 28.07.1931 & $00: 27$ & 81.7 & 65 & 1000 & & 29.1 & & 5470 & 5602 & -132 \\
\hline 32 & 28.07.1931 & 01:10 & 81.6 & 68.1 & 500 & & 30.8 & & 5400 & 5480 & -80 \\
\hline 33 & 28.07 .1931 & 02:07 & 81.6 & 73.5 & 500 & & 33.5 & & 4980 & 5193 & -213 \\
\hline 34 & 28.07 .1931 & 03:08 & 81.4 & 80.5 & 500 & & 36.2 & & 4600 & 4848 & -248 \\
\hline 35 & 28.07 .1931 & $03: 34$ & 81.2 & 83.9 & 500 & 46.5 & 37 & 9.5 & - & 4693 & - \\
\hline 36 & 28.07 .1931 & 04:08 & 81.2 & 87 & 500 & 50.5 & 37.7 & 12.8 & - & 4506 & - \\
\hline 37 & 28.07 .1931 & $04: 10$ & 81.2 & 87.5 & 500 & & 37.8 & & 4110 & 4476 & -366 \\
\hline 38 & 28.07 .1931 & 05:06 & 80.9 & 92.8 & 500 & & 37.8 & & 3640 & 4218 & -578 \\
\hline 39 & 28.07 .1931 & 08:08 & 79.6 & 94 & 1150 & & 35.2 & & 4190 & 4401 & -211 \\
\hline 40 & 28.07 .1931 & 09:09 & 78.9 & 96.2 & 1150 & & 33.2 & & 4510 & 4414 & 96 \\
\hline 41 & 28.07 .1931 & $10: 12$ & 78 & 101.2 & 1150 & & 28.5 & & 4480 & 4328 & 152 \\
\hline 42 & 28.07 .1931 & $10: 50$ & 78 & 102.3 & 1150 & & 27.8 & & 4490 & 4271 & 219 \\
\hline 43 & 28.07 .1931 & $11: 16$ & 77.4 & 102.2 & 1150 & & 26.3 & & 4370 & 4429 & -59 \\
\hline 44 & 28.07.1931 & $12: 08$ & 76.1 & 103.3 & 1150 & & 22 & & 4530 & 4752 & -222 \\
\hline 45 & 28.07 .1931 & 13:04 & 75.5 & 104.4 & 1150 & & 19.6 & & 4530 & 4902 & -372 \\
\hline 46 & 28.07 .1931 & $14: 09$ & 74.7 & 104.1 & 1100 & & 18 & & 5250 & 5191 & 59 \\
\hline 47 & 28.07 .1931 & $15: 00$ & 74.6 & 102.2 & 1100 & & 19.6 & & 5340 & 5302 & 38 \\
\hline 48 & 28.07 .1931 & $16: 10$ & 74.5 & 98.7 & 1050 & & 22.4 & & 5680 & 5515 & 165 \\
\hline 49 & 28.07.1931 & $17: 07$ & 74.7 & 95.4 & 1050 & & 25.1 & & 5340 & 5655 & -315 \\
\hline 50 & 28.07 .1931 & 18:08 & 74.7 & 91.9 & 800 & & 27.1 & & 5750 & 5912 & -162 \\
\hline 51 & 28.07 .1931 & $19: 08$ & 74.7 & 87.8 & 800 & & 28.6 & & 5580 & 6243 & -663 \\
\hline 52 & 28.07 .1931 & $20: 00$ & 74.7 & 85.5 & 800 & & 29.2 & & 6040 & 6437 & -397 \\
\hline 53 & 28.07 .1931 & $21: 14$ & 73.9 & 82.7 & 800 & & 28.6 & & 6680 & 6972 & -292 \\
\hline 54 & 28.07 .1931 & $23: 14$ & 74.1 & 78.9 & 350 & & 29.1 & & 6770 & 7232 & -462 \\
\hline 55 & 29.07.1931 & 00:05 & 74.7 & 77 & 250 & & 29.6 & & 7420 & 7172 & 248 \\
\hline 56 & 29.07 .1931 & 01:03 & 75.4 & 74.3 & 250 & & 29.7 & & 7110 & 7211 & -101 \\
\hline 57 & 29.07 .1931 & $01: 26$ & 75.8 & 72.5 & 250 & 35.9 & 29.8 & 6.1 & - & 7136 & - \\
\hline
\end{tabular}


Table 1. Continued.

\begin{tabular}{|c|c|c|c|c|c|c|c|c|c|c|c|}
\hline $\begin{array}{l}\text { Point } \\
\text { No. }\end{array}$ & Date, UT & $\begin{array}{l}\text { Time UT, } \\
\text { h, min }\end{array}$ & $\begin{array}{r}\text { Latitude } \\
{ }^{\circ} \mathrm{N}\end{array}$ & $\begin{array}{r}\text { Longitude } \\
{ }^{\circ} \mathrm{E}\end{array}$ & $\begin{array}{r}\text { Height of } \\
\text { flight, } \mathrm{m}\end{array}$ & $\begin{array}{r}D, \\
\text { measured }\end{array}$ & $\begin{array}{r}D, \text { IGRF-11 } \\
\text { epoch } 1930\end{array}$ & $\Delta D$ & $\begin{array}{r}H, \\
\text { measured }\end{array}$ & $\begin{array}{r}H, \text { IGRF-11 } \\
\text { epoch } 1930\end{array}$ & $\Delta H$ \\
\hline 58 & 29.07 .1931 & 02:04 & 76.2 & 71 & 200 & & 29.7 & & 7220 & 7105 & 115 \\
\hline 59 & 29.07 .1931 & 02:40 & 76.5 & 69.5 & 200 & & 29.4 & & 7250 & 7108 & 142 \\
\hline 60 & 29.07 .1931 & 03:40 & 76.4 & 66.8 & 1300 & & 28.3 & & 7280 & 7335 & -55 \\
\hline 61 & 29.07 .1931 & $03: 46$ & 76.4 & 66.8 & 1300 & & 28.3 & & 7360 & 7335 & 25 \\
\hline 62 & 29.07 .1931 & $04: 51$ & 75.8 & 63.8 & 1300 & & 26.7 & & 7530 & 7769 & -239 \\
\hline 63 & 29.07 .1931 & $05: 45$ & 75.1 & 61.6 & 1300 & & 25.4 & & 7810 & 8188 & -378 \\
\hline 64 & 29.07 .1931 & 07:07 & 74.2 & 58.8 & 1300 & & 23.7 & & 8530 & 8725 & -195 \\
\hline 65 & 29.07 .1931 & 08:06 & 73.6 & 57.6 & 1300 & & 22.8 & & 8910 & 9042 & -132 \\
\hline 66 & 29.07 .1931 & $09: 55$ & 73.3 & 55.2 & 800 & & 21.5 & & 9290 & 9303 & -13 \\
\hline 67 & 29.07 .1931 & $10: 48$ & 72.3 & 55 & 1200 & & 21 & & 9480 & 9726 & -246 \\
\hline 68 & 29.07 .1931 & $12: 49$ & 70.4 & 50.8 & 700 & & 18 & & 10350 & 10730 & -380 \\
\hline 69 & 29.07 .1931 & $13: 49$ & 69.5 & 48.9 & 1320 & & 16.6 & & 10880 & 11183 & -303 \\
\hline 70 & 29.07 .1931 & $14: 45$ & 68.5 & 47.5 & 1320 & & 15.5 & & 11330 & 11654 & -324 \\
\hline 71 & 29.07 .1931 & $15: 35$ & 67.7 & 46.1 & 1150 & 16.7 & 14.4 & 2.3 & - & 12036 & - \\
\hline 72 & 29.07 .1931 & $16: 08$ & 67.1 & 45.2 & 1150 & & 13.7 & & 11850 & 12314 & -464 \\
\hline 73 & 29.07 .1931 & $17: 08$ & 66.1 & 43.7 & 1150 & & 12.5 & & 12480 & 12770 & -290 \\
\hline 74 & 29.07 .1931 & $18: 15$ & 65.4 & 42.2 & 1150 & & 11.5 & & 12980 & 13094 & -114 \\
\hline 75 & 29.07 .1931 & $18: 53$ & 64.9 & 41.2 & 1150 & & 10.8 & & 13350 & 13320 & 30 \\
\hline 76 & 29.07 .1931 & $21: 32$ & 62.8 & 36.1 & 1000 & & 7.4 & & 13860 & 14246 & -386 \\
\hline 77 & 29.07 .1931 & $23: 22$ & 61.6 & 33.8 & 1100 & & 5.9 & & 14630 & 14751 & -121 \\
\hline
\end{tabular}

$D$ - in degrees ( 8 observations), $H$ - in nanotesla (69 measurements), $\Delta$ - difference between the measurements and the IGRF-11 model,

Calculation: http://wdc.kugi.kyoto-u.ac.jp/igrf/point/index.html.

Table 2. Values of $D$ at the nodes of the grid with a spacing of $4^{\circ}$ according to the data of B. P. Weinberg and I. M. Rogachev (1933) for the epoch 1935 in the Arctic region. The anomalous values of $D$ are given in italics.

\begin{tabular}{cccccccccccc}
\hline Latitude degrees & \multicolumn{10}{c}{ Longitude, degrees epoch 1935 } \\
\cline { 2 - 13 } & 57 & 61 & 65 & 69 & 73 & 77 & 81 & 85 & 89 & 93 & 97 \\
\hline 87 & 20.58 & 22.73 & 24.71 & 29.18 & 30.17 & 32.68 & 35.40 & 3900 & 42.50 & 4600 & 46.92 \\
83 & 23.83 & 24.63 & 27.40 & 33.30 & 31.32 & 33.57 & 37.47 & 37.17 & 36.88 & 39.37 & 39.42 \\
79 & 22.57 & 25.45 & 26.53 & 28.40 & 30.30 & 30.83 & 32.33 & 33.83 & 44.08 & 33.50 & 44.00 \\
75 & 20.60 & 23.05 & 25.62 & 27.83 & 28.45 & 27.58 & 27.50 & 27.33 & 27.00 & 26.73 & 24.67 \\
71 & 20.18 & 22.00 & 23.45 & 24.42 & 26.52 & 25.32 & 24.55 & 23.67 & 22.12 & 20.50 & 18.50 \\
\hline
\end{tabular}

Ljungdahl (1931), who carried out magnetic measurements, wrote that the card experienced irregular oscillations and vibrations during the flight, which led to errors in determination of $D$. Comparison of the $D$ values measured during the flight with the ground-based data gave an error of $0.9^{\circ}$ and $1.6^{\circ}$ in the regions of towns Stettin and Arkhangelsk, respectively. Ljungdahl pointed out that it was difficult to determine exactly the error in $D$ measurements on board the airship. However, it was highly improbable that it exceeded $\pm 2-3$ degrees.

\section{Results of measurements of $H$ and $D$ geomagnetic field components and their analysis}

Table 1 summarizes results of measurements of the horizontal component of the geomagnetic field $H$ and its declination $D$ (Ljungdahl, 1931; Ellsworth and Smith, 1932). In addi- tion, Table 2 lists coordinates of the observation points and also the magnitudes of the geomagnetic field components calculated by using the IGRF-11 model for the epoch 1930 (http://wdc.kugi.kyoto-u.ac.jp/igrf/point/index.html). Differences between experimental and model values of $H$ and $D$ are also given in Table 3.

During the flight, the expedition had charts of geomagnetic field elements in the Northern Hemisphere for the epoch 1930 presented by Fisk (1931). Even the first measurement of $D$ in the flight from Franz Josef Land to Severnaya Zemlya (point No. 35, Table 1) drew attention of the researchers to an anomalous $D$ that exceeded the expected value almost by $10^{\circ}$. For this reason the determination of $D$ was repeated and an anomalous value of $D$ (point 36, Table 1) was again obtained, but this time the difference was more than $10^{\circ}$ (Ljungdahl, 1931). 
Table 3. Differences between experimental and model $D$ at the nodes of the grid with a spacing of $4^{\circ}$ in the Arctic region. The anomalous values of $\Delta D$ are given in italics.

\begin{tabular}{clllllllllll}
\hline Latitude degrees & \multicolumn{10}{c}{ Longitude degrees epoch 1935 } \\
\cline { 2 - 13 } & 57 & 61 & 65 & 69 & 73 & 77 & 81 & 85 & 89 & 93 & 97 \\
\hline 87 & -1.19 & -2.24 & -3.41 & -2.03 & -4.06 & -4.51 & -4.69 & -3.97 & -3.17 & -2.37 & -4.07 \\
83 & -1.21 & -3.08 & -2.84 & +0.68 & -3.5 & -3.27 & -1.14 & -2.97 & -4.5 & -2.94 & -3.47 \\
79 & -2.74 & -2.1 & -3.09 & -3.04 & -2.7 & -3.4 & -2.75 & -1.66 & +8.69 & -1.2 & +10.64 \\
75 & -3.31 & -2.76 & -1.83 & -0.97 & -1.34 & -2.79 & -2.96 & -2.66 & -1.87 & -0.29 & +0.25 \\
71 & -1.55 & -1.28 & -1.09 & -1.05 & +0.51 & -0.76 & -1.08 & -0.97 & -0.74 & +0.07 & +1.18 \\
\hline
\end{tabular}

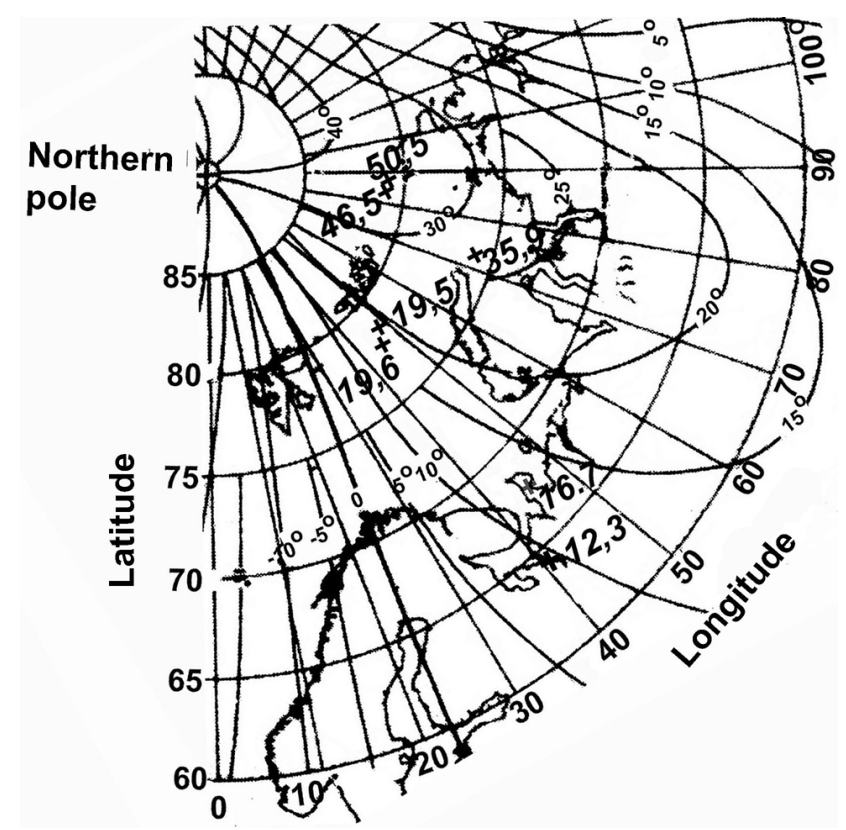

Figure 5. Chart of isogonic lines $D$ for the epoch 1930 according to Fisk (1931) showing the points of measurements of magnetic declination on board the airship.

Figure 5 shows a chart of isogonic lines $D$ for the epoch 1930 according to Fisk (1931) where the points of $D$ measurements at the flight route are marked. It is evident from Fig. 5 that $D$ measured in the high-latitude part of the flight route indeed differs by approximately $10^{\circ}$ from the values of $D$ given on the chart of isogonic lines. In addition, there is a noticeable (about $6^{\circ}$ ) difference between the cartographic and experimental values of $D$ near the northern end of Novaya Zemlya (point 57 , Table 1 ). It is unlikely that this difference is due to measurement inaccuracy. Ljungdahl (1931) supposed that the error in declination measurements on board the airship did not exceed 2-3 degrees. The difference between the experimental and model as well as cartographic data for the remaining points (except the three points mentioned above) was within the limits of this inaccuracy.

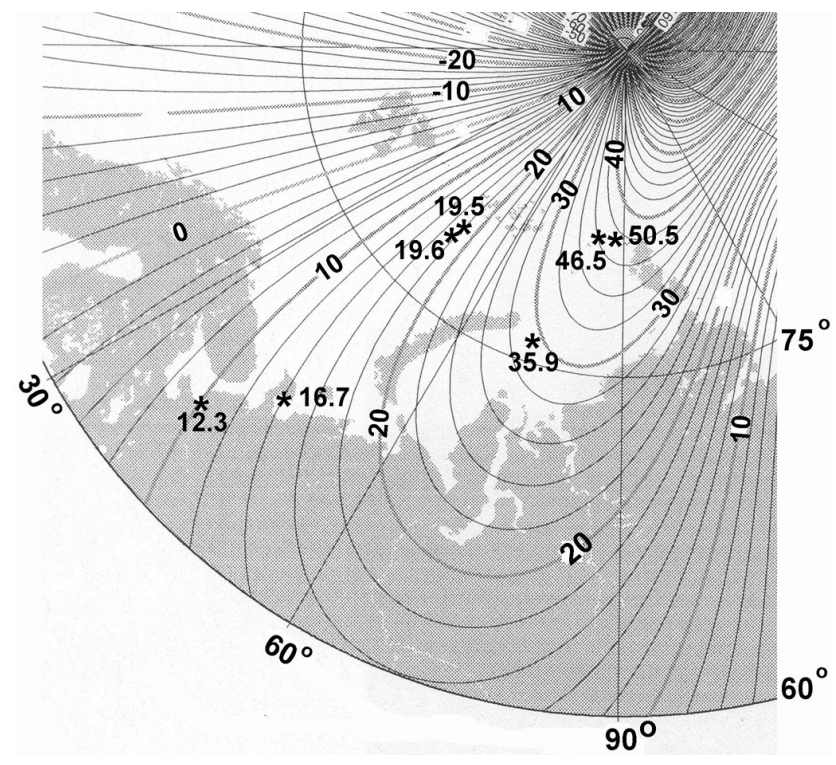

Figure 6. Chart of isogonic lines $D$ for the epoch 1930 according to the IGRF-11 model showing points of magnetic declination measurements on board the airship.

It can be supposed that the geomagnetic field in the Arctic region was insufficiently studied to the 1930s and the chart of $D$ plotted by Fisk did not show all spatial features in the $D$ distribution. For this reason, we plotted a chart of isogonic lines $D$ for the epoch 1930 according to the IGRF-11 model and marked the points at which $D$ was measured in the flight (Fig. 6). As this chart demonstrates, the anomaly in $D$ in the region of Novaya Zemlya (point 57, Table 1) is approximately $6^{\circ}$ instead of $10^{\circ}$. However, at high latitudes (points 35 and 36, Table 1) anomalous values of $D$ remain at a level of $10^{\circ}$ and more.

Ljungdahl (1931) and Ellsworth and Smith (1932) put forward the idea that anomalous values of $D$ could be due to local magnetic anomalies. In order to understand whether this hypothesis is correct, let us consider the geomagnetic data obtained in subsequent years.

B. P. Weinberg and I. M. Rogachev (1933) plotted a grid of $D$ values with a spacing of 4 degrees in longitude and latitude 


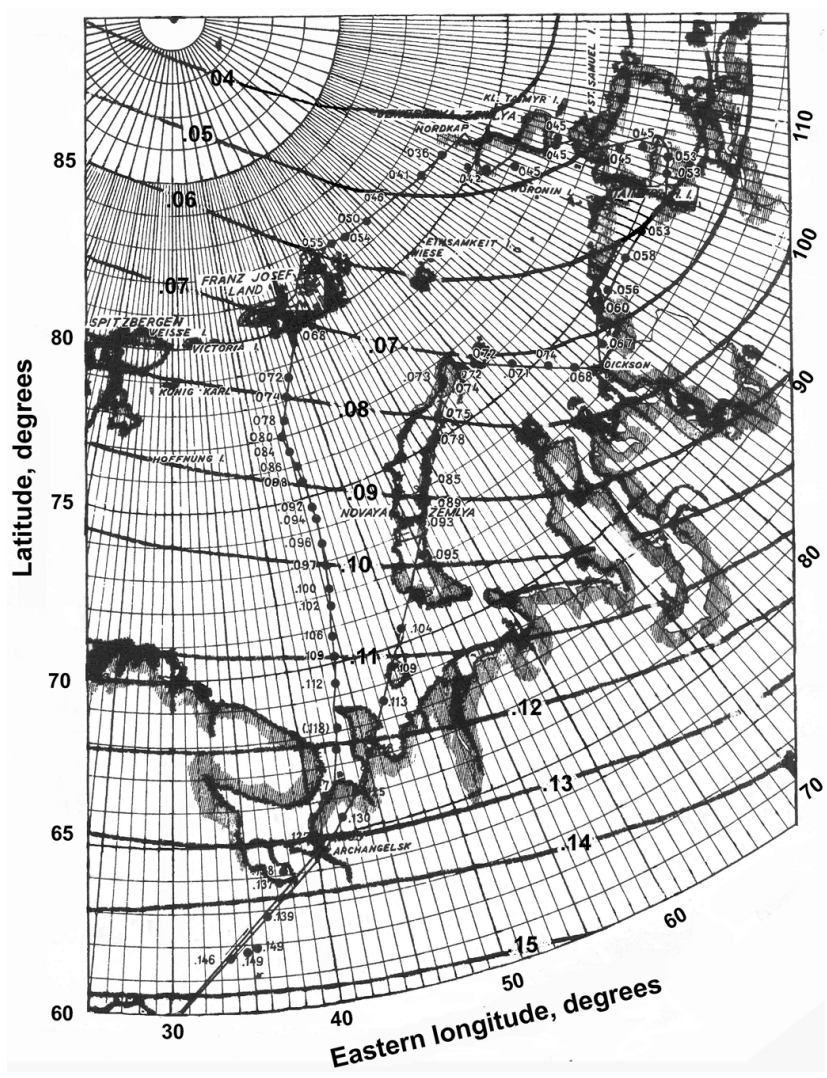

Figure 7. Map with the airship flight route showing results of measurements of $H$ and isodynamic lines $H$ from the chart of Fisk (1931) for the epoch 1930. The values of the $H$ component are in $\mathrm{mT}$.

on the basis of all available data on determination of declination $D$ on the USSR territory and adjacent seas for the epoch 1935. This grid of $D$ values includes the Arctic region. Table 2 lists values of $D$ determined from the experimental data at the nodes of the grid from 57 to $97^{\circ} \mathrm{E}$ and 71 to $87^{\circ} \mathrm{N}$, i.e., in the region of the high-latitude part of the airship flight. Table 2 lists differences $\Delta D$ between the $D$ values calculated by Weinberg and I. M. Rogachev and declination $D$ inferred from the IGRF-11 model for the epoch 1935.

It can be seen from Table 2 that there are regions of anomalous $D$ of $8-10.5^{\circ}$ at latitude $79^{\circ} \mathrm{N}$ in the longitude range $89-97^{\circ}$. Thus, independent experimental data confirm that anomalous values of $D$ measured on the airship could be due to local magnetic anomalies.

When considering results of determination of the horizontal $H$ component during the flight, Ljungdahl (1931) and Ellsworth and Smith (1932) did not report on any anomalous features in the behavior of measured $H$. However, analysis of Table 1 as well as Fig. 7, which shows results of $H$ measurements during the flight and isodynamic lines $H$ from the chart of Fisk (1931) for the epoch 1930, reveals the points at which the magnitude of $H$ differs from the cartographic

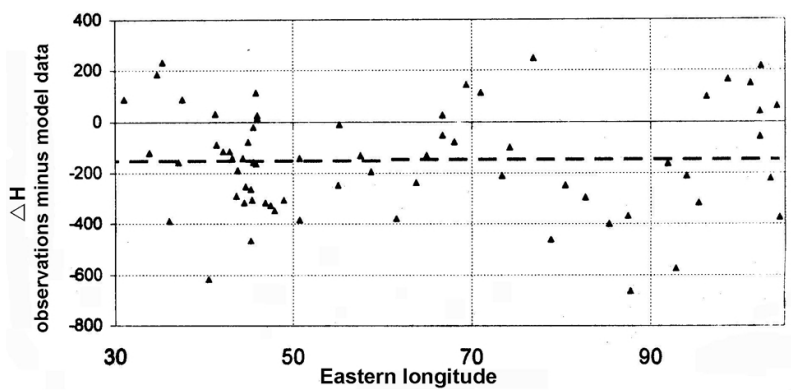

b

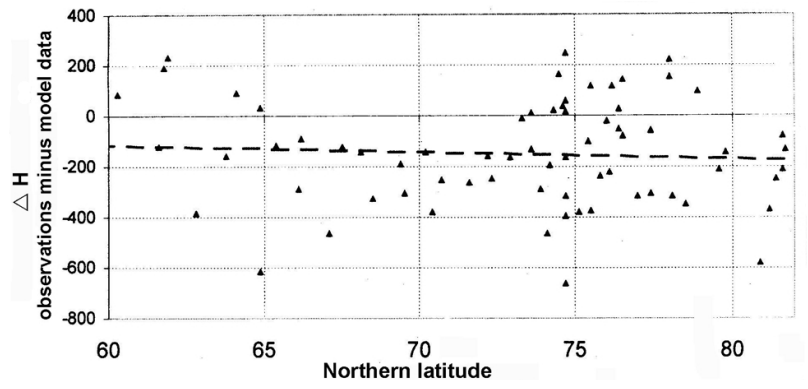

a

Figure 8. Differences between $\Delta H$ observed on board the airship and calculated according to the IGRF-11 model for the epoch 1930 as functions of latitude (a) and longitude (b) of observation points.

and model values by hundreds of nT. For example, it can be seen that the measured $H$ in the high-latitude part of the flight route near the region of anomalous $D$ is $3600 \mathrm{nT}$ (point $38 \mathrm{~b}$ in Table 1), while, according to the chart of isodynamic lines, $H$ at this point must be about $4400 \mathrm{nT}$ (Fig. 7). There are appreciable differences (by hundreds of nT) in the measured $H$ and cartographic data in the region of Severnaya Zemlya and Dikson Island. Table 1 lists differences between $H$ measured in the flight and $H$ calculated from the IGRF-11 model for the epoch 1930. Recall that in the European flight of the airship, the inaccuracy of $H$ determination did not exceed, as a rule, $100-110 \mathrm{nT}$. Only at two points was the inaccuracy 180 and $320 \mathrm{nT}$, which was attributed by the researchers to local geomagnetic anomalies. Another situation is observed for $H$ measurements in the Arctic flight. Only at 17 of 69 points of $H$ measurements the difference between the measured and model values was less than $100 \mathrm{nT}$. In 12 cases it was less than $150 \mathrm{nT}$, but in 21 cases it exceeded $250 \mathrm{nT}$, and at points $8,38,51$, and 72 this difference was more than $500 \mathrm{nT}$. Figure 9 presents differences between the observed and model values of $\Delta H$ as functions of latitudes and longitudes of observation points. It is evident from Fig. 8 that the average difference between the observed values of $H$ and the model values is close to $-200 \mathrm{nT}$, which considerably exceeds the possible inaccuracy of measurements.

The differences agree well with the level of anomalies in the field modulus. According to the chart plotted by Petrov et al. (2004) from Russian Geological Institute (VSEGEI), values of $\Delta T$, which is anomalous in the region, considered reach $300-500 \mathrm{nT}$. Figure 9 shows a chart of anomalies in the 


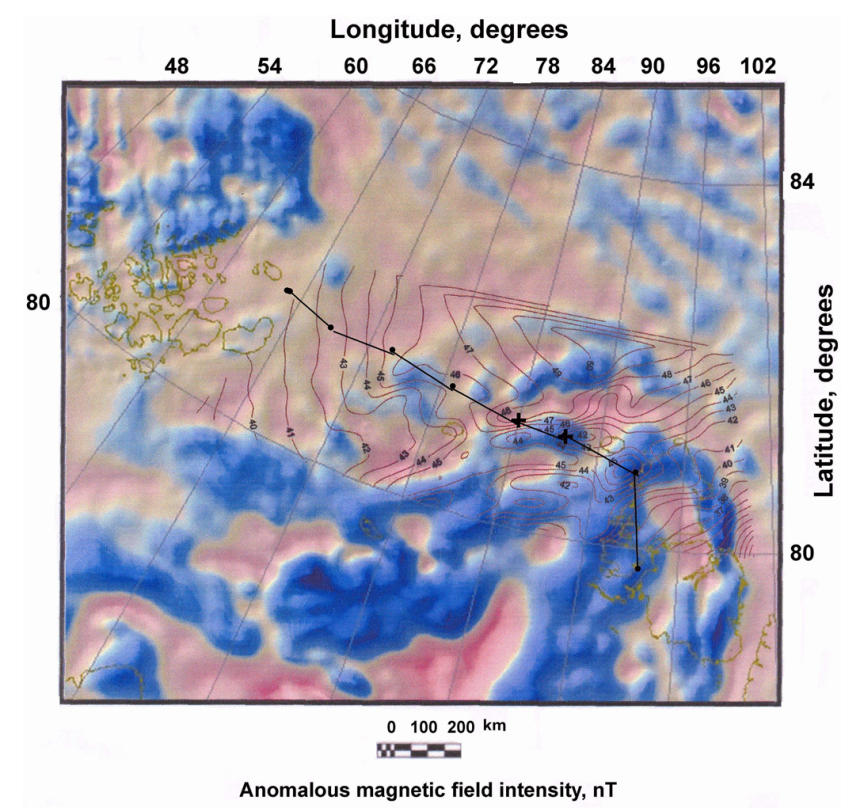

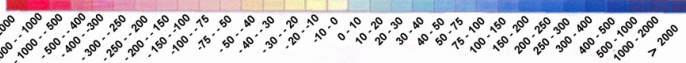

Figure 9. Chart of anomalies in the modulus of geomagnetic field strength for the high-latitude part of the airship flight route with isogonic lines of magnetic declination. The crosses mark the points of determination of $D$ during the flight.

modulus of geomagnetic field strength for the high-latitude part of the flight with isogonic lines of magnetic declination. It is clear that the points of determination of declination on board the airship (shown by crosses) (points 35 and 36, Table 1) lie in the region of anomalous geomagnetic field with a very complicated structure. This is confirmed by modern data on the structure of the anomalous magnetic field in the region of the high-latitude part of the flight. An anomaly in $\Delta H$ (at point 38, see Table 1) is also observed at this part of the flight route, the anomaly reaches $-578 \mathrm{nT}$ which is also seen, as noted above, in Fig. 7. One more anomalous region of $\Delta H$ includes the western coast of the Taimyr Peninsula, estuary of Enisey river, and the area from Dikson Island to the northern end of Novaya Zemlya (points 49-55, Table 1). Deviations of $H$ from the model values reach here $663 \mathrm{nT}$ and usually exceed $250 \mathrm{nT}$. Approximately in the same region there is point 57 (Table 1) with an anomalous value of $\Delta D=6.1^{\circ}$. Thus, measurements of $H$ in the airship flight reveal an anomalous magnetic field structure in the Barents and Kara sea regions. This result is supported by the structure of $\Delta T$. Note that Ljungdahl (1931) and Ellsworth and Smith (1932) did not pay attention to this fact.

It should be emphasized that the modern charts of $\Delta D$ for the Arctic water areas adjacent to the Russian territory in the north are too general. Detalization of these charts sharply differs from that of the maps of territories, and for this reason the anomalous nature of declination at points 35,36 , and 57 of the airship flight route (Table 1) is not directly confirmed by these maps. However, complex analysis of modern data on the structure of the anomalous magnetic field $\Delta T$ and $\Delta H$ in the region of the airship flight shows that the anomalous values of magnetic declination at these points are caused by local magnetic anomalies rather than errors in $D$ measurements. In order to obtain an adequate cartographic presentation of these anomalies in the magnetic field components, new magnetic surveys should be carried out.

To estimate possible errors in determination of geomagnetic field components during the Graf Zeppelin flight, it is also necessary to analyze geomagnetic disturbances during the time interval of the flight, especially because only single measurements of $H$ and $D$ were carried out at each point. In our case this is even more important because of a radiocommunication blackout during the flight from Franz Josef Land to Severnaya Zemlya (Krenkel, 1978), which could be due to development of geomagnetic disturbances at high latitudes. In 1931, two magnetic observatories: Matochkin Shar on Novaya Zemlya $\left(73^{\circ} 25^{\prime} \mathrm{N}, 55^{\circ} 24^{\prime} \mathrm{E}\right)$ and the Sodankylä Observatory in Finland $\left(67^{\circ} 22^{\prime} \mathrm{N}, 26^{\circ} 38^{\prime} \mathrm{E}\right)$, were operating at the Arctic latitudes in the region of Kara and Barents seas. Unfortunately, the authors of the paper could not get any information on where the archive of magnetic records of the observatory Matochkin Shar for 1931 can be found. The records from the observatory Matochkin Shar were collected by the Arctic and Antarctic Research Institute in Saint-Petersburg from 1933. Therefore, geomagnetic field disturbances during the airship flight can be analyzed on the basis of the data of the Sodankylä Observatory, which is located in the auroral zone and also geomagnetic data of mid-latitude British observatories. In the analysis, data on variations in the global $a a$-index and data of astronomical observations of sunspots were used.

Figure 10 shows $X$ component magnetogram for the days of the airship flight, $K$-indexes of the Sodankylä Observatory (http://sgodatahtt.sgo.fi/pubmag/ Kindex/KINDEX1930-1939.txt) and $a a$-indexes (ftp://ftp.ngdc.noaa.gov/STP/).

The reports of British observatories Lerwick, Eskdalemuir, Stonyhurst, and Abinger for 1931 (http://www.geomag. bgs.ac.uk/data_service/data/yearbooks/yearbooks.html) indicate that the days of $23,24,25,26$, and 28 July were moderately disturbed, and 27 July was magnetically quiet. The Stonyhurst College Observatory (Results of the Geophysical and Solar Observations. 1931. Stonyhurst College Observatory, 1933) reported a large-amplitude SC and a subsequent development of an intense magnetic storm on 26 June 1931. In 26 days and $12 \mathrm{~h}$ after the storm commencement, on 23 July, geomagnetic disturbances with much smaller amplitudes were observed, and only in $6 \mathrm{~h}$ afterwards, a development of moderate geomagnetic disturbances occurred. There were no visible sunspots and solar faculae near the central solar meridian. Therefore, the geomagnetic disturbances during the time interval of the airship flight had a recurrent 


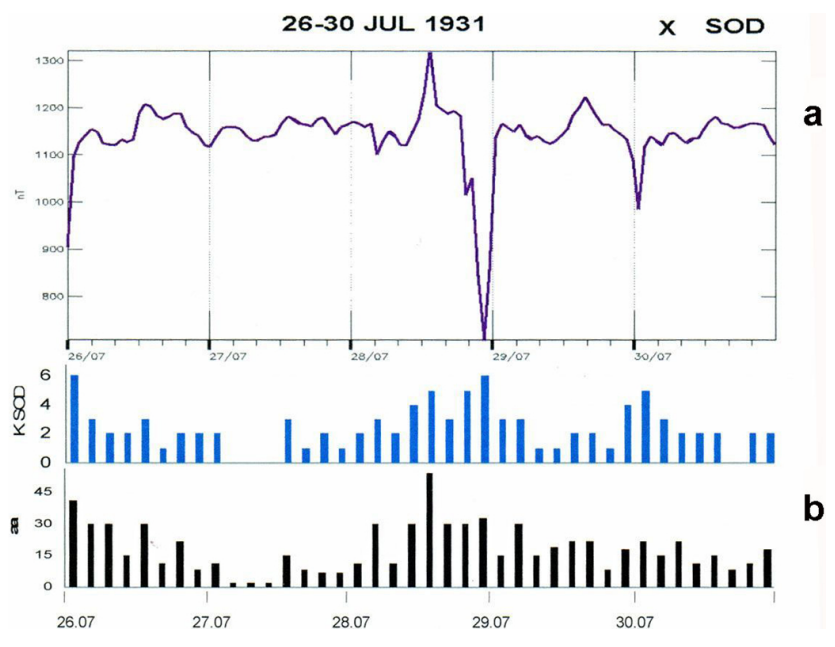

Figure 10. Magnetograms of the Sodankylä Observatory: (a) $-X$ component for the time interval from 26 till 30 July 1931; (b) - variations in $K$ indexes of the Sodankylä Observatory and $a a$-indexes (in nT) for the time interval from 26 till 30 July 1931.

character. According to the observatory observations, the solar activity during this time interval was of type I, i.e., there were one or several small spots on the solar disk. According to the data and terminology of British observatories, the geomagnetic disturbances during the period of flight were as follows: 26.07 - small, 27.07 - calm, 28.07 - moderate and 29.07 - small. Moderate disturbances began about 12:00 UT, i.e., in the second half of the day (Results of the geophysical and solar Observations, 1931. Stonyhurst College Observatory, 1933; Result of the Magnetical \& Meteorological Observation made at the Abinger Magnetic Station, Surrey and Royal Observatory, Greenwich respectively in the year 1931, 1933).

As one can see from Fig. 10, the measurements of geomagnetic disturbances of the Sodankylä Observatory are similar to those of the British observatories. During the first day of the flight (26 July 1931), the disturbances were considerable only at the beginning of the day. The airship was at the Sodankylä Observatory latitude at about 20:00 UT. Judging by the magnetogram, in the evening (UT) of this day the disturbances did not exceed 70-80 nT. The airship measurements at point 8 at $17: 16 \mathrm{UT}$ gave $\Delta H$ equal to $-615 \mathrm{nT}$, which pointed to a local magnetic anomaly. During 27 July 1931, the geomagnetic field disturbance was low (Fig. 10). However, anomalous values of $\Delta H>250 \mathrm{nT}$ at points 14 and 15 (Table 1) and $\Delta H>300 \mathrm{nT}$ at points $24,25,27$ and 29 were detected, which could point to the effect of local anomalies on the double compass readings. In contrast to preceding days, on 28 July geomagnetic disturbances set in and became especially pronounced in the second half of the day (UT), which is clearly observed in the magnetogram of the Sodankylä Observatory (Fig. 10). In the first half of 28 July (UT), when disturbances were not so strong, the airship flew

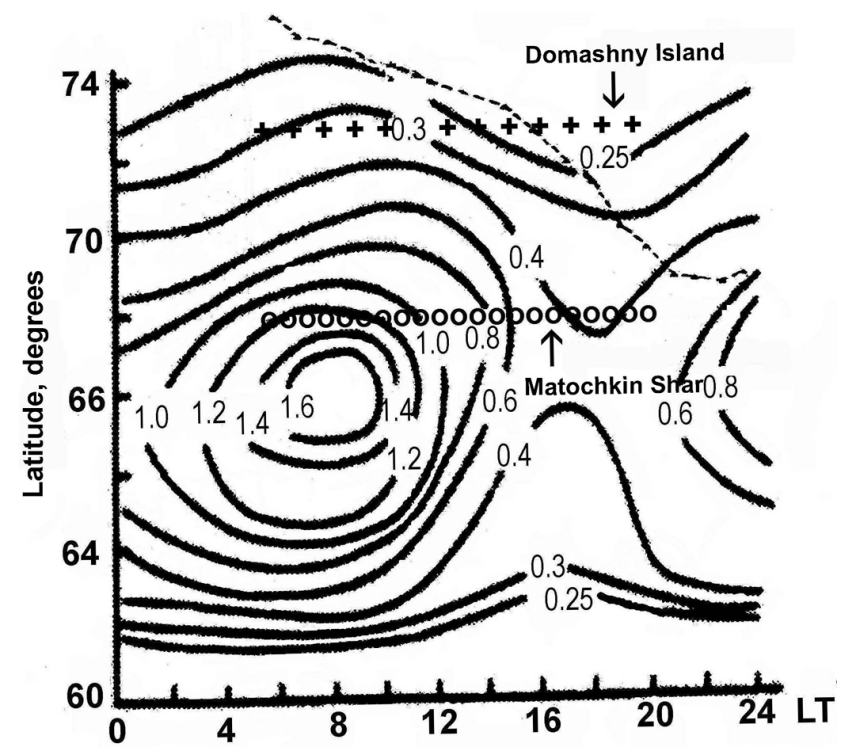

Figure 11. Averaged picture of distribution of auroral absorption (frequency $32 \mathrm{MHz}$ ) at high latitudes of the Northern Hemisphere at geomagnetic disturbance $K_{p}=4$ in the coordinates: local time - corrected geomagnetic latitude (CGL) according to Zhulina et al. (1989). The figures at the isolines give absorption in decibels. The crosses mark the locations of Domashniy Island according to CGL, and the circles show the locations of the observatory Matochkin Shar (CGL).

from midnight to 06:30 UT from Franz Josef Land to Novaya Zemlya. Just at this time, at 03:00-04:00 UT, anomalous $\Delta D$ of 9.5 and 12.8 degrees (points 35 and 36 , Table 1 ) and $\Delta H$ of -366 and $578 \mathrm{nT}$ (points 37 and 38, Table 1) were measured. It is difficult to attribute anomalous values of $\Delta D$ and $\Delta H$ in this region to the effect of geomagnetic disturbances because the geomagnetic field disturbance was weak. However, it is possible that a magnetic substorm could make contributions to anomalous values of $\Delta D$ and $\Delta H$ : possibly $\Delta H$ to $100 \mathrm{nT}$, but not 360-570 nT.

From $05: 00$ to $12: 00 \mathrm{UT}$, or from 11:00 to 18:00 LT, the airship tried to establish radiocommunication with the base of the expedition. However, because of the short-wave radiocommunication blackout the contact with the expedition base on Domashniy Island failed. Note that there were 3 transmitters on board the airship, and the base on Domashniy Island had a good (for those times) radiostation that operated from October of 1930 at short waves in the range 20-70 m (http://vivovoco.rsl.ru/VV/JOURNAL/ NATURE/11_03/NORD.HTM; Gromov, 1932).

In order to demonstrate the airship position with respect to the region of possible ionospheric disturbances which could be responsible for the radiocommunication blackout, Fig. 11 shows the averaged picture of auroral absorption (frequency $32 \mathrm{MHz}$ ) at high latitudes of the Northern Hemisphere (Zhulina et al., 1989). The dashed line in Fig. 11 shows the flight route in the coordinates: LT - corrected 
geomagnetic latitude (CGL). The locations of Domashniy Island (crosses) and the observatory Matochkin Shar (circles) according to CGL are given. This figure shows that the radio link between the airship and Domashniy Island (and also between the airship and the observatory Matochkin Shar, where the receiver was also installed) is almost entirely in the region of an increased auroral shortwave absorption. The region is projected into the magnetosphere to the periphery of the external radiation belt $L \approx 7-12$ (Domashniy Island: $79.0^{\circ} \mathrm{N}, 91.0^{\circ} \mathrm{E} ; \mathrm{CGL}=72.5 ; L=11$; Matochkin Shar: $\left.73.25^{\circ} \mathrm{N}, 55^{\circ} \mathrm{E} ; \mathrm{CGL}=67.7 ; L=6.9\right)$ from which energetic (subrelativistic 40-300 keV and relativistic $>300 \mathrm{keV}$ ) electrons responsible for $D$ region ionization and shortwave absorption precipitate. Thus, the radiocommunication blackout with the land can be explained by an increasing geomagnetic activity and development of ionospheric disturbances during this time interval at high latitudes, where the airship was at that time: the $a a$-index grew to 54 , and the $K$ index at the Sodankylä Observatory increased to 4-5.

Because of unfavorable weather conditions, the airship could not reach the island and the task of the airship landing in this region was not solved. The next day of the flight (29 July 1931) was characterized by a lower geomagnetic disturbance. However, anomalous values of $\Delta H$ were measured on the flight route from Novaya Zemlya to Arkhangelsk (230-460 nT). They appreciably exceeded possible observation errors. Thus, anomalous geomagnetic field values were revealed on this part of the flight route as well.

\section{Conclusions}

To implement the idea of F. Nansen on the possibility of using airships for scientific research in the Arctic, an Arctic flight of the Graf Zeppelin airship was carried out on 26-30 July 1931, in the region of Barents and Kara seas. In its flight, the airship reached latitudes higher than $81^{\circ} \mathrm{N}$ and flew over Arctic regions which were poorly studied in those times. Among the scientific tasks solved by the expedition was measurements of the $H$ and $D$ geomagnetic field components. This was actually the first aeromagnetic survey at the Arctic latitudes. The researchers paid attention to the fact that anomalous values of $D$ that differed by 8 $12^{\circ}$ from the expected values were detected during the flight from Franz Josef Land to Severnaya Zemlya. It was supposed that anomalous $D$ was due to local magnetic anomalies rather than observation errors.

Analysis of $H$ and $D$ measured on board the airship, based on modern and archival data on the geomagnetic field structure in the Barents and Kara sea region, has confirmed that the measured anomalous values of $D$ were not due to observation errors, actually they reflected a real complicated geomagnetic field structure at the point of $D$ determination. Almost no new information on the thin declination structure in this region has appeared from those times, which makes these unique measurements even more valuable. Analysis of archival and modern geomagnetic data has revealed that anomalous geomagnetic field structure in this region manifested itself not only in $D$ but also in changes in the horizontal $H$ component, which was not pointed out by the researchers who carried out the measurements.

To summarize, analysis of the geomagnetic measurements carried out during the Arctic flight of the Graf Zeppelin airship leads to the conclusion that the implementation of the idea of F. Nansen on the use of airships for exploration of the Arctic territories proved to be fruitful. Even the first aeromagnetic survey demonstrated a complicated geomagnetic field structure in the region of the Barents and Kara seas. Unfortunately, the first experience of using airships for scientific exploration of the Arctic did not find continuation.

Acknowledgements. The authors thank anonymous reviewers and HGSS Topic Editor Tamara V. Kuznetsova for constructive comments and criticisms.

Edited by: T. V. Kuznetsova

Reviewed by: three anonymous referees

\section{References}

Eckener, H.: My Zeppelins. Translated from German by Douglas Robinson, London, Putnam \& Co. Ltd., 1958, New York, Arno Press, 1980.

Ellsworth, L. and Smith, E. H.: Report of preliminary results of the aeroarctic expedition with "Graf Zeppelin", 1931, The Geographical Review, V. XXII, The American Geographical Society, New York, 61-82, 1932.

Fisk, H. W.: Isomagnetic charts of the Arctic Area. Trans. Amer. Geophys. Union, Twelfth Ann. Meeting, 30 April and 1 May 1931, National Research Council, Washington, 134-139, 1931.

Gromov, B. V.: Wreck of Arktika, Moscow, Molodaya Gvardiya, 180 pp., 1932.

Grotewahl, M.: Bericht über die Versuchsfahrt des Bidlingmaier'schen Doppelkompasses mit dem Luftschiff Graf Zeppelin, Terr. Magn. Atmos. Electr., 35, 226-230, 1930.

Krenkel, E.: RAEM is My Callsign, Moscow Progress, 364 pp., 1978.

Ljungdahl, G. S.: Preliminary report of the magnetic observations made during the aeroarctic expedition of the Graf Zeppelin, 1931, Terr. Magn. Atmos. Electr., 36, 349-355, doi:10.1029/TE036i004p00349, 1931.

Nansen, F.: The proposed Arctic expedition in the Graf Zeppelin, Geogr. J., 1, 67-70, 1930.

Petrov, O. V., Morozov, A. F., Lipilin, A. V., Kolesnikov, V. I, Litvinova, T. P., and Myasnikov, F. V.: Chart of anormalous magnetic field $(\Delta T)_{a}$ of Russia and adjacent water areas, Scale $1: 5000000$, VSEGEI, 2004.

Results of the Magnetic \& Meteorological Observations made at the Abinger Magnetic Station, Surrey and Royal Observatory, Greenwich, Respectively in the year 1931, Under the direction of Sir Frank Dyson, London, H.M.S.O., 1933. 
Results of Geophysical and Solar Observation. 1931, Stonyhurst College Observatory, Blackburn, Tomas Briggs Ltd, 1933.

Weinberg, B. P. and Rogachev, I. M.: Catalogue of magnetic determinations in USSR and adjacent countries. Part III. Determination made from 1926 to 1930, Central Geophysical Observatory, Leningrad, 1933.

Wilkins, H.: Under the North Pole: The Wilkins-Ellsworth Submarine Expedition, New York, Brewer, Warren \& Putnam, 347 pp., 1931.
Wichman, E.: Two routes to the arctic: under the ice with the nautilus, through the air with the Graf Zeppelin, ARCHIVE, A Journal of Undergraduate History, V. 4, University of WisconsinMadison, History department, 24-41, November 2002.

Zhulina, E. M., Kishcha, P. V, and Shchuka, T. I.: Statistical model of auroral absorption at different magnetic activities, in: Ionosfernyye Issled, No. 46, Moscow, 81-85, 1989. 